\title{
Can universal pre-kindergarten programs improve population health and longevity? Mechanisms, evidence, and policy implications
}

\author{
Peter Muennig \\ Columbia University, 600 W. 168th St., 6th Floor, New York, NY 10032, United States
}

\section{A R T I C L E I N F O}

\section{Article history:}

Available online $\mathrm{xxx}$

\section{Keywords:}

Educational attainment and health

Socioeconomic disparities and health

Health policy

\begin{abstract}
A B S T R A C T
Recent research has found that children who attended pre-kindergarten programs in childhood were more likely to be healthy as adults. One intuitive way of improving population health and longevity may therefore be to invest in pre-kindergarten programs. However, much of the research linking prekindergarten programs to health is very recent and has not been synthesized. In this paper, I review the mechanisms linking pre-kindergarten programs in childhood to adult longevity, and the experimental evidence backing up these linkages. I conclude with a critical exploration of whether investments in pre-kindergarten programs could also serve as investments in public health.
\end{abstract}

๑) 2014 Elsevier Ltd. All rights reserved.

\section{Introduction}

Children with fewer opportunities to obtain a high-quality education face a cascade of socio-economic challenges throughout their lives, and these challenges are thought to ultimately increase their risk of premature death (Ross and Wu, 1995). As one example of these lifelong challenges, those who do not obtain an education credential will find it extremely difficult to find a quality job that offers high pay, a safe work environment, provides health insurance, and affords a life in a low-crime neighborhood (Grossman, 1997; Kawachi et al., 2010; Ross and Wu, 1995). While it receives relatively little attention in the media, the overall health burden associated with lower educational attainment is larger in the US than it is for obesity (Muennig et al., 2010). Moreover, the adverse health effects of having less educational attainment are increasing over time (Olshansky et al., 2012). One intuitive approach to addressing this growing mortality disparity is to improve schooling in ways that reduce a youth's chances of dropping out of school (Woolf et al., 2007).

Of all schooling enhancements that increase both educational attainment and health, pre-kindergarten programs perhaps hold the most promise. Pre-kindergarten programs have both been shown to improve high school graduation rates and to improve health in ways that are highly likely to reduce premature death in adulthood (Campbell et al., 2014; Currie, 2001; Muennig et al., 2009; Palfrey et al., 2005; Reynolds et al., 2001; Schweinhart et al., 2005). In theory, pre-kindergarten programs could reduce

E-mail address: pm124@columbia.edu. the growing health disparities by educational attainment in the US, and therefore serve as a powerful policy lever for improving public health (Woolf et al., 2007). However, neither the evidence base nor the theoretical models linking pre-kindergarten programs in childhood to health and longevity in adulthood have been fully synthesized.

In this paper, I ask whether investments in pre-school programs can also serve as public health investments. Broadly speaking, the task is to simply link children's exposure to pre-kindergarten to their health in adulthood using strong (e.g., experimental or quasiexperimental) studies. If the effect seems real and reasonably large, then we can conclude that the answer is probably yes. I therefore begin this paper with a review of the literature linking exposure to pre-kindergarten programs in childhood to health in adulthood.

However, it is extremely helpful to the reader to also have a sense of how prekindergarten programs accomplish this feat. One very important clue in this sleuth work is get a sense of what it is that those who are not exposed to pre-kindergarten programs are dying from. For instance, if lung cancer were much more likely in those who did not attend pre-kindergarten programs, then we might suspect that smoking is a major risk factor for poor health outcomes. Working backwards, we would then want to show that smoking is more common in non-attendees. Finally, we would wish to speculate as to what it is about not attending a pre-kindergarten program that would put one at higher risk of smoking. Cognitively enhanced children in a pre-kindergarten program may be "promoted" into a peer group that is less likely to smoke. Likewise, it could be that non-attendees are less likely to obtain a high school diploma, and are therefore more likely to work in lower wage jobs where more people smoke. Alternatively, it could be that non- 
attendees have less health knowledge. While all of these possibilities are speculative, it does help the reader get a "big picture" sense of how pre-school programs work. Without this big picture (which I attempt to draw), the mechanisms remain abstract in the minds of policymakers and researchers alike.

I conclude by then drawing from the evidence base evaluating whether pre-kindergarten programs produce adult health and longevity and my speculations as to why this might be to then ask if it is reasonable to conclude that investments in pre-school programs can also serve as public health investments.

\section{Evidence that pre-kindergarten will improve adult health}

Most of the research linking educational attainment or cognitive ability to premature death was historically built from correlational studies. Therefore, some researchers have questioned whether the differences in mortality by educational attainment arise from the underlying innate psychological, sociological, and demographic characteristics of those youth who do poorly in school, rather than to schooling and parenting (Fuchs, 2004). For example, it is possible that people who finished their education are also more likely to be forward looking, and thus less likely to smoke or engage in other health risks that lead to premature death (Fuchs, 2004). Thus, such researchers argue that the difference in longevity between high school graduates and high school dropouts has nothing to do with exposure to the educational system, but is rather merely a spurious correlation.

From a health policy perspective, it is a critically important distinction. If better-educated people predominantly live longer because of their underlying characteristics, then investments in effective schooling programs will not work. Because there is no practical way to control for confounders like underlying personality characteristics in prospective longitudinal studies, the only definitive way to understand whether investments in early childhood education will reduce mortality differences by educational attainment is via randomized controlled trials (RCTs), or at least quasiexperimental approaches (Kawachi et al., 2010; Levin and Belfield, 2007; Lleras-Muney, 2005).

In addition to spurious correlation, we must consider factors that schooling can do little to influence. For one, while one's intelligence quotient (IQ) gains can happen as late as adolescence, IQ is relatively stable after age 8 or so (Kolb and Whishaw, 2009; Ramsden et al., 2011). (The standard measure for "intelligence" or "cognitive ability" in the literature is one's IQ but it should be recognized that this is an imperfect measure of intelligence.) Therefore, if it cognitive ability more broadly that matters for adult health, compulsory education will have less impact on premature death because it tends to impact educational attainment later in life.

In addition to the timing of schooling, schooling interventions will likely meet different levels of success depending upon the socio-economic characteristics of the students they serve. For instance, poverty is widely believed to exerting its adverse effects on human health even before conception. Throughout their development, children living in poverty are more likely to be exposed to toxins (such as lead), physical abuse, sexual abuse, poor nutrition, and psychological stress (Adler and Ostrove, 1999; Chen et al., 2002). Classroom programs will do little to address these threats to mental health, physical health, and cognitive development.

In fact, many of the programs reviewed here also coupled prekindergarten programs with parent education programs that may account for some or even all of the health effects I report here. Therefore, it is difficult to disentangle the impacts of pre- kindergarten programs on cognition, on non-cognitive outcomes, or on family effects.

On the other hand, children from poor families are generally starting from a much lower baseline for IQ and health than children from more privileged families. Therefore, children from poor families can realize much greater improvements than better off children even if they do not reach their full biological potential.

Fortunately, none of these theoretical concerns matter if solid experimental studies are available that show that a particular education program in childhood produces health in adulthood.

\subsection{Pre-kindergarten programs and health}

Pre-kindergarten programs have been evaluated using RCTs (Campbell et al., 2014; Muennig et al., 2011a,b; Muennig et al., 2009), at least one regression discontinuity analysis (Ludwig and Miller, 2007), and case-control studies (Palfrey et al., 2005; Reynolds et al., 2001). These all show an impact on behavioral risk factors for health or actual measures of health. Because some of the participants in the control groups received some treatment in regular community pre-kindergarten programs, the effect sizes I present below may be larger than they appear.

One caveat that I should mention up front is that the health outcomes differ between the studies I discuss here. These include behavioral risk factors (e.g., smoking), self-rated health status, various diseases or conditions, and mortality. Therefore, we must assume that when one is sick, rates himself or herself in poor health, or engages in behavioral risks such as smoking that the end result-even if not measured directly in these studies-is premature death. There is strong evidence that these are fair assumptions (Schnittker and Bacak, 2014).

\subsubsection{The Perry Preschool Program (PPP)}

Initiated in 1962, PPP randomized 123 3- or 4-year-old severely disadvantaged African American children to either receive no intervention or to receive a 2-year program of $2.5 \mathrm{~h}$ of interactive instruction daily coupled with 1.5 -h weekly home visits. Treated students realized stark social and economic benefits by age 40 . The baseline IQ of the participants was 78 (Schweinhart et al., 2005). It remained at this level in the control group but improved to normal levels within a few years in the treated group. If one accounts for the net reductions in incarceration, increased earnings, decreased welfare utilization, and health benefits, the treated group appeared to realize economic gains over his or her lifetime by upwards of 1 million dollars per student, depending on how the analysis and projections are estimated (Heckman et al., 2010; Nores et al., 2005). Many of these gains were realized from important public health outcomes: reduced crime and incarceration (Golembeski and Fullilove, 2005). Because both engagement in crime and incarceration are highly predictive of longevity, one would expect mortality reductions over the lifetime of children who were exposed to PPP.

Two separate teams of researchers re-evaluated PPP to explore whether it might have also produced health impacts. The most complete and recent of these studies entailed an additional wave of data collection that includes laboratory testing of participants who are now in their 50s. The results, which were generated by a team similar to those who recently re-evaluated ABC (Campbell et al., 2014), were embargoed at the time of publication (personal communication, Larry Schweinhart).

A different study by Muennig et al. (2009) used a sensitive method of detecting joint impacts across multiple health and behavioral risk factor outcome measures. This approach is called "seemingly unrelated regression (Zellner, 1962)." In that study, in which I participated, we found that treated children realized statistically significant reductions in unhealthy behaviors by age $40-\mathrm{a}$ 
powerful predictor of premature death (Muennig et al., 2009). Behavioral risk factors aside, the overall health benefits by age 40 were less clear for two reasons. First, we adhered very strictly to our a priori model specification, in which we erroneously double counted arthritic conditions in the original model specification, a condition that was higher in treated relative to control children. By removing either of these double counted variables, health impacts become statistically significant. Second, behavioral risk factors, particularly smoking, tend not to manifest as improvements in health or longevity until later in life (Doll and Peto, 1976). Therefore, some time must pass before the statistically significant reductions in behavioral risk factors translate into improved health among treated participants relative to control participants.

\subsubsection{The Carolina Abecedarian Project ( $A B C)$}

The $A B C$ intervention was began prior to birth and involved more hours of child and parental instruction than most prekindergarten programs. 111 very low-income African-American infants were randomized to receive parental counseling, nutritional supplements, and pre-kindergarten schooling (versus nutrition supplements alone). By the time participants reached 21 years, just 104 participants were still alive and eligible for interview. ABC produced statistically significant improvements in test scores throughout school and higher graduation rates relative to the control group.

In a recently published follow up study using that cohort, $A B C$ was found to produce large health benefits for children in the treatment group (Campbell et al., 2014). These included large reductions in participants' Framingham risk score-a combined measure of multiple risk factors for premature death including high blood pressure, cholesterol, and blood sugar.

Using the same methods applied to our PPP study, our team similarly found that $A B C$ improved health in adulthood even though the evaluation was much earlier in life than the Campbell et al. (2014) study or the PPP cohort (Muennig et al., 2011a,b). Specifically, we find that the joint effect of treatment on lower rates of depression, fewer health problems, and fewer hospitalizations were statistically significant $(p<0.05)$. Likewise, the joint effect of treatment on 11 behavioral risk factors was statistically significant $(p<0.05)$.

\subsubsection{Head Start}

Head Start is a national pre-kindergarten program that, like PPP and $A B C$, provides both in-class cognitive enhancement and parental instruction components (DHHS, 2012). It is targeted toward families who earn less than $130 \%$ of the Federal Poverty Line. It is not universal, however, and its budget is quite low for a nationwide education program at just over $\$ 8$ billion dollars, so there is considerable room for expansion.

A large RCT of Head Start was recently conducted by the Department of Health and Human Services (now with follow up through the 3rd grade). In this study, some of the control participants were treated and some of the treated students subsequently moved to the control group (Department of Health and Human Services, 2013). This significantly reduces the observed effect sizes and statistical power. Nevertheless, the study found "statistically significant differences between the Head Start group and the control group on every measure of children's preschool experiences in the first year of the study" (Department of Health and Human Services, 2013; iv). These effects disappeared after the first year of the study. However, they also similarly "faded" and then returned in PPP, so longer-term follow up is needed (Finn et al., 2001).

It will be a long time before health impacts of the aforementioned Head Start RCT can be assessed for health impacts. However, a regression discontinuity study of the broader Head Start program (unrelated to the above mentioned RCT) showed reductions in mortality for children aged 5 to 9 (Ludwig and Miller, 2007). These reductions in childhood mortality were thought to arise from the funding and technical assistance provided by the Office of Economic Opportunity in 1965 to develop Head Start programs. This funding and technical assistance, which was delivered to the 300 poorest counties in the US, also appeared to produce improvements in educational attainment.

\subsubsection{Other studies}

In separate analyses, $\mathrm{ABC}$ and a case-control matched prekindergarten program (the Brookline Early Education Project or, BEEP) also showed lower rates of depression in treated participants (McLaughlin et al., 2007; Palfrey et al., 2005). While studies are not all consistent, depression (one of the most important public health threats) has been linked to premature death (Berkman et al., 2003). In addition, a larger case-control study found that the Chicago Child-Parent Center (CPC) program produced reductions in criminal behavior, an important predictor of premature death (Golembeski and Fullilove, 2005; Reynolds et al., 2001). The CPC was unique in that the program was large, with 989 carefully matched participants in the case and control groups.

\subsection{Can we conclude that these programs improve health and longevity?}

Taken together, the literature on pre-kindergarten programs provides much more convincing evidence that pre-kindergarten interventions improve health and longevity. However, it is also important to explore other studies that explore the education-health relationship using a causal framework.

One study that raises doubts about the health-mortality relationship is the Tennessee Project Student-Teacher Achievement Ratio (STAR) RCT. Project STAR was a large, multi-center RCT. Like pre-kindergarten programs, class size reduction in the early years can be considered an early education intervention. This is because they attempt to provide an enhanced cognitive environment prior to age 8 , before IQ is more or less stable. Project STAR randomized 11,601 children to receive instruction in small (13-17 students), regular (22-25 students), or regular sized classes plus a certified teacher's aide within 79 schools in diverse settings within Tennessee. Children assigned to small classes earned higher test scores, achieved higher rates of high school graduation, and were more likely to take college entrance exams relative to children assigned to regular classes (Finn et al., 2001; Finn et al., 2005; Krueger and Whitmore, 2001), however, they were more likely to die prematurely than the treatment group (Muennig et al., 2011a,b).

The increase in mortality seen in the treated children appeared at a very early age and continued roughly through the participants' early 20s. We speculated that this increase in mortality arose because children in smaller classrooms become more extroverted, and that youth may be more likely to find trouble together; virtually all of the excess deaths were related to accidents, drug overdoses, drowning, and gunshot wounds. However, these impacts were time limited. A re-analysis of the data showed that the excess mortality had disappeared by age 30 , and trended toward a crossover, with lower mortality in the treated group later in life (author's unpublished data). Therefore, while this study initially appeared to contradict the findings of other early education programs, it does not appear that these adverse impacts were enduring.

Finally, we must consider the literature on compulsory schooling laws because: 1) it contains some of the rare causal studies linking educational attainment to health and 2) prekindergarten programs, like compulsory schooling laws, produce 


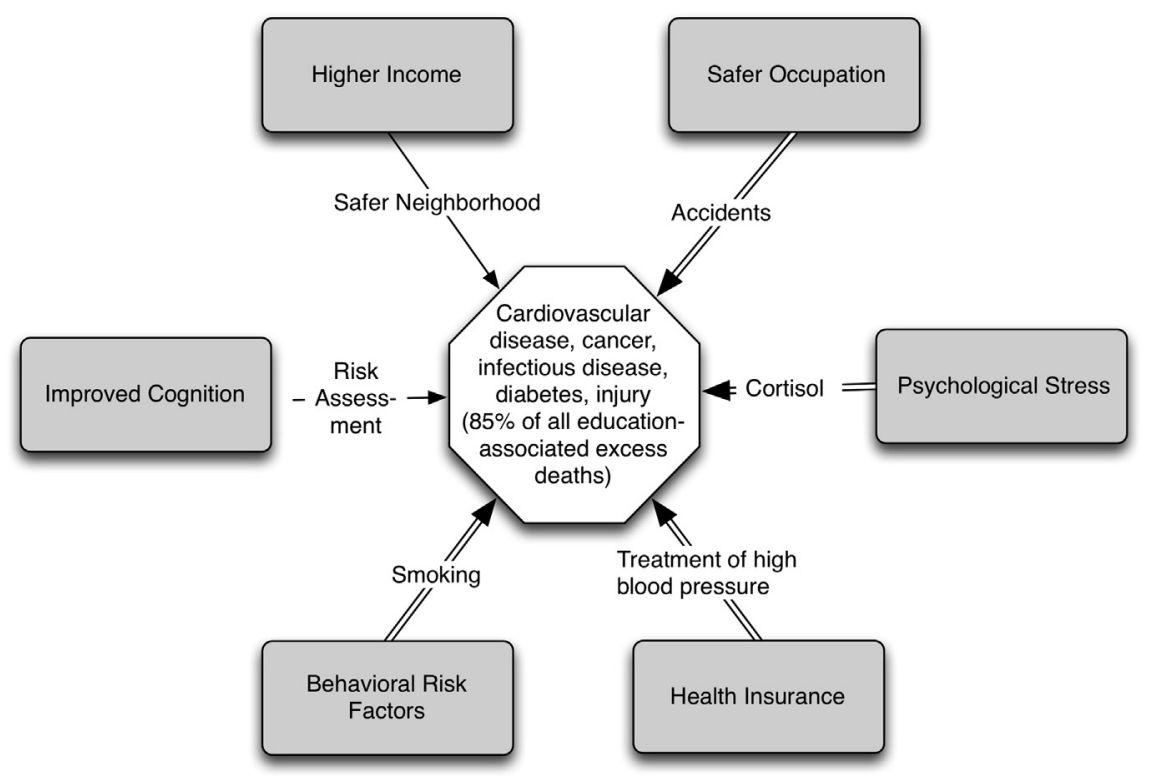

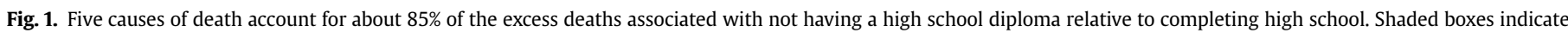

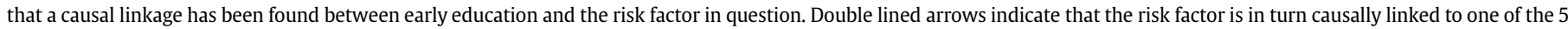
causes of premature death in the center of the figure. One example of a hypothesized mediator is shown within each arrow in the diagram.

higher educational attainment. Compulsory education requires students to attend school through grade school, middle school, or high school. Instrumental variable (IV) analyses show large effects. For instance, the first of a series of such analyses showed that the impact of educational attainment on mortality is large, with one year of additional education reducing one's mortality risk over 10 years by $30 \%$ (Lleras-Muney, 2005). Regression discontinuity, on the other hand, shows no effect of additional schooling on mortality in the UK (Clark and Royer, 2008). Both approaches require a number of assumptions that may not hold with such broad sweeping analyses. Moreover, compulsory schooling laws impact children after their IQ has stabilized and hardly constitute an improvement in the quality of one's education experience the way that prekindergarten programs do.

\section{Mechanisms linking pre-kindergarten programs to mortality}

In the previous section, I present evidence that pre-kindergarten produce health and reduce premature death later in life. One major remaining question is how this occurs. Because having good schooling in life influences one's future in so many ways, it is quite difficult to pinpoint the ways in which health benefits might be derived. These include cognitive pathways, such improved math and reading skills (which improve one's chances of being promoted through grades and ultimately graduating). They also possibly include non-cognitive pathways, such as higher self-confidence and promotion into advanced placement classes (which can lead to very different peer networks).

In this section, I explore how exposure to pre-kindergarten programs might impact a child's life trajectory in ways that also improve that child's health. I work forward, drawing from sources such as the Chicago Longitudinal Study (Ou and Reynolds, 2008) but also work backwards from the time of their death drawing from what we know about the causes of death among those with lower educational attainment (Wong et al., 2002). I use an overarching conceptual framework I developed in conjunction with the Robert Wood Johnson Foundation (RWJF, 2008).
While there are no equivalent studies on pre-kindergarten programs per se, differences in educational attainment can mostly be traced to 5 causes of death (Wong et al., 2002). Were these causes of death removed, the difference in life expectancy between high school dropouts and graduates would fall from roughly 6-9 years to roughly one year (give or take 3 months). These causes include cardiovascular disease (35 percent of all deaths), cancer (27 percent of all deaths), infection ( 9 percent of all deaths), injury ( 5 percent of all deaths), lung disease ( 5 percent of all deaths), and diabetes (4 percent of all deaths).

Fig. 1 shows these 5 causes of death and the risk factors for disease that are believed to "cause" these causes of death (Mokdad et al., 2004). For one, consider behavioral risk factors, such as smoking. The double arrow in the diagram indicates that there is causal data linking smoking to at least one of the causes of death in the center of the figure, in this case cardiovascular disease and lung cancer (Anthonisen et al., 2005). Higher income has been linked to all 5 causes of death, but while some mechanisms are intuitive (e.g., income should afford living in a safer neighborhood, which should in turn reduce one's risk of murder), none have been proven (Kawachi et al., 2010). A safer occupation is clearly linked to reduced injury (e.g., from working with dangerous heavy machinery) and is associated with reduced cancer (e.g., from working with dangerous industrial chemicals) (Johnson et al., 1999). Psychological stress has been linked to all 5 causes of death (McEwen, 1998). Health insurance has been linked to fewer deaths due to hypertension but, interestingly, none of the other causes of death in the figure (Newhouse and Rand Corporation. Insurance Experiment Group, 1993).

The shaded boxes in Fig. 1 indicate that the risk factor in question has been directly or indirectly causally linked to prekindergarten programs. Fig. 2 fills in the gaps, allowing us to both work backwards from mortality and forwards from prekindergarten programs to develop a hypothetical model (RWJF, 2008). Here, the same notations are used, with single arrows indicating that the linkage between the boxes is supported only by correlational data and a double arrow indicates that the linkage is supported by at least one experimental study. 


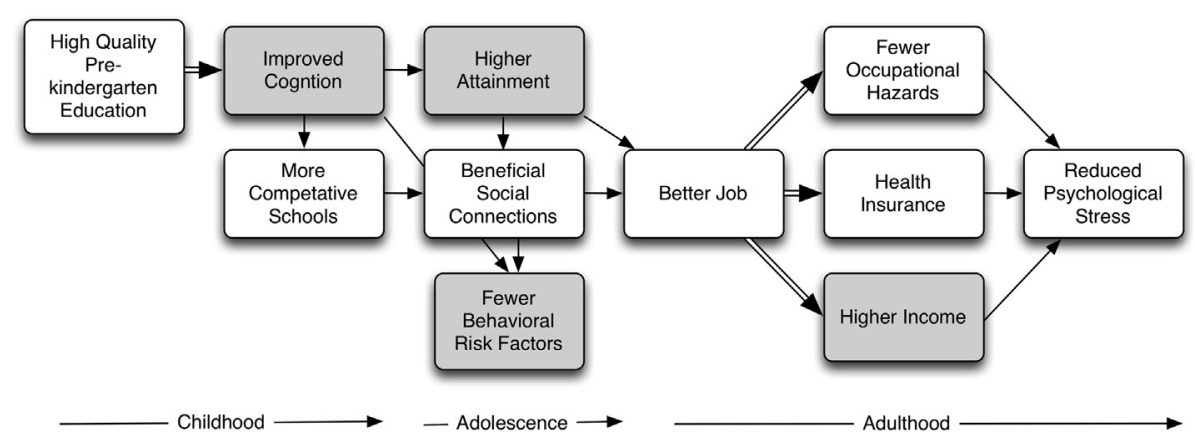

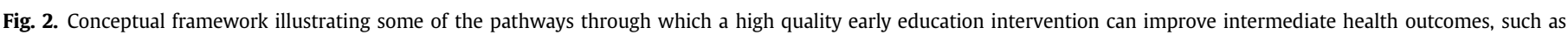

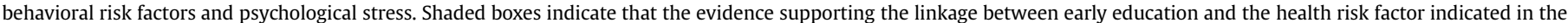

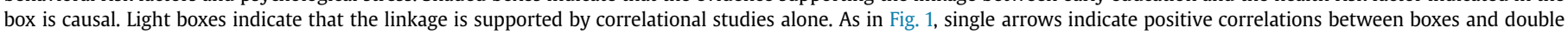
arrows indicate causal linkages between boxes.

Consider the example of improved cognition, which appears in Fig. 1 on the left of the diagram and in the first box to the right of "High Quality Pre-kindergarten Education" in Fig. 2. Three randomized trials and various case control studies have shown that intensive pre-kindergarten programs produce enhanced cognitive ability (Campbell and Ramey, 1994; Currie, 2001; Finn et al., 2001; Palfrey et al., 2005; Schweinhart et al., 2005). However, only correlational studies have linked higher cognitive ability to the 5 causes of death in Fig. 1 (Gottfredson, 2004). These authors speculate that those with stronger cognitive ability may be better able to understand medical instructions, navigate social bureaucracies, understand the risks associated with smoking or eating poorly, and possibly even drive more defensively, resulting in fewer accidents. This way, enhanced cognition can be linked to all 5 causes of death in Fig. 1.

Similarly, on the 3rd box from top left of Fig. 2, we see that exposure pre-kindergarten has been causally linked to higher educational attainment, as indicated by the shaded box (Campbell e al., 2002; Krueger and Whitmore, 2001; Schweinhart, 2004). This higher attainment is thought to arise in part by enhanced cognition (single line). Of course, one could imagine a non-cognitive role here, too (not shown to simplify diagram). As more extroverted children win favor with teachers who then give them more attention. In this sense, the benefit could be similar to that of reducing class sizes (Finn et al., 2001). Likewise, both improved cognitive ability and higher educational attainment are strongly and consistently correlated with having fewer behavioral risk factors (as indicated by the shaded box), but this relationship has not been experimentally studied (as indicated by the single arrow) (Gottfredson, 2004; Muennig, 2007).

Following Fig. 2 from left to right, one might speculate that the advantage of enhanced cognitive ability builds upon itself incrementally over time. Children who are better academic performers in the early years are more likely to be tracked into advanced placement classes or promoted to more competitive schools, both prerequisites for placement in a competitive university (J.D. Finn et al., 2001). This is a route to falling in with a "good crowd" as advanced placement might also create "beneficial social connections"-peers that are more likely to work hard, less likely to use legal or illegal drugs, and more likely to provide connections to jobs later in life (Link and Phelan, 1995). This may explain why prekindergarten programs are causally linked to reduced behavioral risk factors for poor health (shaded box at bottom of Fig. 2). If so, pre-kindergarten programs have the ability to motivate changes in one's belief structures not only through the content of education programs, but also through non-cognitive routes, such as exposure to peers who place a higher value on academic achievement as the benefits of early education programs unfold over time.

Moving to the center of Fig. 2, we see that a degree is needed for a good job; it is not possible to become a doctor or electrical engineer without a degree (Carneiro and Heckman, 2003; p. 45). Job quality, in turn, can influence health in many different ways over the course of one's career (Ross and Mirowsky, 1995).

First, starting on the top middle right box of Fig. 2, we see that job quality is linked to occupational hazards. Recall that accidents constitute one of the 5 education-associated causes of death represented in Fig. 1. Common sources of job-related deaths include traffic accidents among commercial drivers (e.g., truck, taxi, or delivery), construction accidents, accidents involving the use of heavy machinery (e.g., farm or factory equipment), and chemical exposures (e.g., automobile exhaust for highway toll workers) (Johnson et al., 1999).

In the next box down, we see that quality health insurance is linked to having a high quality job (Grossman, 1997; Ross and Wu, 1995). While it may seem intuitive that health insurance is linked to health, two experimental studies show that the benefits are more limited than one might think (Baicker et al., 2013; Newhouse and Rand Corporation. Insurance Experiment Group, 1993). In an earlier study by Newhouse and Rand Corporation. Insurance Experiment Group (1993), previously uninsured participants randomized to receive private health insurance only benefited if they were hypertensive. Hypertension is a major risk factor for cardiovascular disease, the number one education-associated cause of death in Fig. 1. In a later experiment by Baicker et al. (2013) that focused on Medicaid, participant's enjoyed financial protection from catastrophic medical bills, increases in preventive screening, and reductions in depression, but no improvements in blood pressure, cholesterol, or blood sugar. While this raises doubts about the earlier study, the Medicaid study was underpowered and has not yet examined mortality as an outcome measure.

A good job also leads to higher income (shaded, bottom right), an outcome that has been causally linked to pre-kindergarten programs (Nores et al., 2005). While income is linked to lower stress, more sleep, and residence in safer neighborhoods with less crime, traffic, and pollution (Burdette and Whitaker, 2004; Liu and Tanaka, 2002; Rundle et al., 2009), experimental studies have produced mixed and very confusing results linking income supplementation to health (Kawachi et al., 2010; Kehrer and Wolin, 1979). Of course, government income supplementation is very different from earned income. In this latter category, the evidence base is weak (Kawachi et al., 2010).

Having a strong social support network, a good job, fewer injuries, health insurance, and higher income can all, in theory, lower 
one's psychological stress (McEwen and Mirsky, 2002). Lower psychological stress is a powerful predictor of one's internal hormonal balance that can increase one's risk of cardiovascular disease, diabetes, infectious disease, and even cancer (McEwen and Mirsky, 2002). Psychological stress is also a powerful determinant of behavioral risk factors. For instance, both studies in humans and experimental studies in animals show that psychological stress impacts one's likelihood of using drugs as well as one's choice of healthy food versus unhealthy food (Cohen et al., 2006; Pomerleau and Pomerleau, 2006; Wilson et al., 2008). Thus, to the extent that pre-kindergarten programs help optimize one's life and therefore reduce stress, they will influence 4 of the 5 education-associated deaths in Fig. 1.

While the result would be unruly for publication, the reader should consider in Fig. 2 more completely. For one, betterconnected people tend to get a better job, and a better job tends to lead to more beneficial social connections (Link and Phelan, 1995). So a reciprocal line could be drawn between the high quality job and beneficial social connections box. Beneficial social connections can, in of themselves, also produce powerful impacts on biomarkers of psychological stress and on mortality (Muennig et al., 2013), and, as mentioned above, stress can be linked back to behavioral risk factors.

The intent of the mechanism section is not to "prove" how prekindergarten programs might improve health, but rather to paint a picture of how they might do so. In the next section, I draw from this framework in asking whether pre-kindergarten programs can serve as a public health intervention.

\section{Policy implications of preschool programs}

The education and health industries in the US together account for nearly a third of the gross domestic product, are the two fastest growing areas of government expenditures, and are perhaps the two most complex areas of domestic policy (Aud et al., 2012; Martin et al., 2012). Public health as a field is moving away from targeting specific risk factors (e.g., anti-smoking campaigns) and toward addressing the social risk factors that predict these population health risks, such as early schooling interventions (Schoeni et al., 2008). Unfortunately, public health is a field that is vastly underfunded, and there has therefore been very little experimental research in this area. Whether such initiatives would actually improve population health and longevity is therefore a major policy question.

While data from reduced class size and early education programs raise some doubt, real health benefits appear to arise from pre-kindergarten programs themselves. Moreover, of the two studies that showed no education-health association, one was less rigorous, not grounded in school quality improvements, and influenced educational attainment at an age well after IQ had stabilized (Clark and Royer, 2008). The other intervention was larger and more rigorous than the pre-kindergarten studies, but only provided mortality follow up through age 30 . With the exception of injury, all of the education-associated deaths in Fig. 1 occur after the age of 40 (Muennig et al., 2011a,b).

Although pre-kindergarten programs have already been shown to be cost-beneficial (Levin et al., 2006), this review suggests that efforts to fund such programs be redoubled, perhaps even if it means diverting health dollars to schooling programs. One could further imagine a future in which corporate responsibility programs for health or life insurance companies might choose to invest in pre-kindergarten programs, forwarding their interests as well as the interests of society as a whole.

It should be kept in mind, however, that the pre-kindergarten experiments have mostly drawn children from severely disadvantaged households. Moreover, these experiments have been performed under well-managed, tightly controlled circumstances that will be difficult to replicate broadly in classrooms across any nation, particularly one as large as the United States. Therefore, many policy-relevant questions remain. First, should such programs be universal, or should they be directed at lowincome households (Barnett et al., 2004)? Second, can such programs be scaled up such that they perform as well as experimental programs (Glennan et al., 2000)?

The smaller cognitive improvement associated with Head Start relative to $\mathrm{PPP}, \mathrm{ABC}, \mathrm{CPC}$, or BEEP raises questions about whether tightly managed and well funded pre-kindergarten programs can be successfully scaled up to the national level (Campbell et al., 2002; DHHS, 2012; Palfrey et al., 2005; Schweinhart et al., 2005). However, a bigger concern, at least for universal pre-kindergarten programs, is that these programs scale poorly not because of poor management or scarcity of resources, but rather because the results of pre-kindergarten studies may not be generalizable to the broader US population.

For instance, children who enroll in Head Start have a baseline IQ that is much higher than children in PPP (with an IQ of 78). As children become increasingly more privileged, they are thought to come much closer to their maximally attainable, or innate, IQ (Turkheimer et al., 2003). Therefore, even if both groups of students were administered the exact same program, PPP students would have had a greater potential to realize improvements than Head Start children. Therefore, the cognitive returns on pre-kindergarten programs diminish with household income. Another argument in favor of redoubling efforts for children in low-income households is that low-income children already receive much less public funding per student than students from middle-income households (Busemeyer, 2007).

If it is true that the most disadvantaged students would benefit most from pre-kindergarten programs, it does not necessarily follow that the best policy approach is to target pre-kindergarten programs to disadvantaged communities. "Means testing," or providing services to those who are most in need and who can least afford to pay for them, leaves such programs politically exposed (Stone, 1997). That is, unless wealthy and powerful groups are benefiting from any given policy, they may be reluctant to pay for it. Moreover, targeted programs often miss low-income communities. Universal programs ensure that all families have access, and therefore are less likely to skip some low-income communities (Barnett et al., 2004). There is also some evidence that children from disadvantaged families benefit more from universal programs than from targeted programs and that children from middle income families benefit as well (Barnett et al., 2004).

In the debate between targeted and universal programs, the macroeconomic side effects of education investments are too often ignored. In Fig. 2, I argue that having a degree can lead to a better job, and that this can produce a cascade of events that leads to a reduction in mortality. However, creating more credentialed graduates may simply raise degree requirements for existing employers because the job markets will be saturated with students with higher credentials. Therefore, one's job quality may not improve in tandem with his or her cognitive prowess.

Likewise, in Fig. 2, I argue that beneficial social connections lead to reductions in mortality. These connections are built when children from low-income households are promoted to higher quality schools that are populated with children from higher income households. However, if the IQ of everyone in the US were raised by 10 points, students would nevertheless continue to sort into the same schools that they are now attending.

However, on closer inspection, these types of arguments may fall apart in a modern globalized economy like the US. Having a 
more cognitively skilled population likely results in a nation that is more competitive in the global marketplace (Friedman, 2005; p. 32). A more skilled workforce can lead to a stronger economy as: 1) productivity gains are realized, 2) global companies that require a highly skilled workforce move into the country, and 3) people who might not otherwise have started a business do so (because their minds have been exposed to new ideas that lead to innovative new businesses). Over time, this could result in better jobs for everyone.

\section{Conclusions}

US President Obama and New York City Mayor Bill DiBlasio have argued for aggressive investments in pre-kindergarten programs. This push has come with considerable debate surrounding the wisdom of such investments despite the growing experimental evidence that pre-kindergarten programs will reduce crime, increase employment, increase job quality, and improve family stability while producing economic returns for every dollar invested (Heckman et al., 2010; Nores et al., 2005).

However, it is increasingly clear that it is possible to improve health and reduce premature death with such investments as well. It will be some time before the pre-kindergarten cohorts age enough to obtain the effect size of their mortality impacts. If prekindergarten programs do prove to be scalable, the population health impacts have the potential to be very large because health disparities by educational attainment are quite large (Galea et al., 2011; Muennig et al., 2010). Therefore pre-kindergarten programs could potentially help solve additional national health concerns such as rising mortality rates in some populations and rapid medical inflation. It could also help reduce the 6-9 year disparity in mortality between high school graduates and high school dropouts, a major priority area of the Department of Health and Human Services.

Despite these benefits, there is a rational and reasonable debate surrounding the ability of national programs, such as Head Start, to effectively replicate the accomplishments seen in randomized controlled trials with long-term follow up. Whether such programs should be universal or targeted is another question that has yet to be answered. As more localities move toward universal education programs, these questions should be easier to answer because more real world quasi-experimental data will become available.

\section{References}

Adler, N.E., Ostrove, J.M., 1999. Socioeconomic status and health: what we know and what we don't. Ann. N. Y. Acad. Sci. 896, 3-15.

Anthonisen, N.R., Skeans, M.A., Wise, R.A., Manfreda, J., Kanner, R.E., Connett, J.E., 2005. The effects of a smoking cessation intervention on 14.5-year mortality randomized clinical trial. Ann. Intern. Med. 142 (4), 233-239.

Aud, S., Hussar, W., Kena, G., 2012. The Condition of Education 2012. US Department of Education, National Center for Education Statistics.

Baicker, K., Taubman, S.L., Allen, H.L., Bernstein, M., Gruber, J.H., Newhouse, J.P., Finkelstein, A.N., 2013. The oregon experiment - effects of medicaid on clinical outcomes. N. Engl. J. Med. 368 (18), 1713-1722. http://dx.doi.org/10.1056/ NEJMsa1212321.

Barnett, S.W., Brown, K., Shore, R., 2004. The Universal vs. Targeted Debate: Should the United States Have Preschool for All?. Available online at: http://nieer.org resources/policybriefs/6.pdf (accessed 05.18.14.).

Berkman, L.F., Blumenthal, J., Burg, M., Carney, R.M., Catellier, D., Cowan, M.J., Schneiderman, N., 2003. Effects of treating depression and low perceived social support on clinical events after myocardial infarction: the enhancing recovery in coronary heart disease patients (ENRICHD) randomized trial. J. Am. Med. Assoc. 289 (23), 3106-3116.

Burdette, H.L., Whitaker, R.C., 2004. Neighborhood playgrounds, fast food restaurants, and crime: relationships to overweight in low-income preschool children. Prev. Med. 38 (1), 57-63.

Busemeyer, M.R., 2007. Determinants of public education spending in 21 OECD democracies, 1980-2001. J. Eur. Public Policy 14 (4), 582-610.

Campbell, F., Conti, G., Heckman, J.J., Moon, S.H., Pinto, R., Pungello, E., Pan, Y., 2014. Early childhood investments substantially boost adult health. Science 343 (6178), 1478-1485. http://dx.doi.org/10.1126/science.1248429.
Campbell, F.A., Ramey, C.T., 1994. Effects of early intervention on intellectual and academic achievement: a follow-up study of children from low-income families. Child. Dev. 65 (3), 684-698.

Campbell, F.A., Ramey, C.T., Pungello, E., Sparling, J., Miller-Johnson, S., 2002. Early childhood education: young adult outcomes from the Abecedarian Project. Appl. Dev. Sci. 6 (1), 42-57.

Carneiro, P., Heckman, J.J., 2003. Human capital policy. In: Heckman, J., Krueger, A. (Eds.), Inequality in America: What Role for Human Capital Policies? MIT Press, Cambridge, MA.

Chen, E., Matthews, K.A., Boyce, T., 2002. Socioeconomic differences in children's health: how and why do these relationships change with age? Psychol. Bull. $128,295-329$.

Clark, D., Royer, H., 2008. The Effect of Education on Adult Mortality and Health: Evidence from the United Kingdom. Available online at: http://www.frbsf.org/ economics/conferences/0806/royer.pdf (accessed 06.04.10.).

Cohen, S., Doyle, W.J., Baum, A., 2006. Socioeconomic status is associated with stress hormones. Psychosom. Med. 68 (3), 414-420. http://dx.doi.org/10.1097/ 01.psy.0000221236.37158.b9 pii:68/3/414.

Currie, J., 2001. Early childhood education programs. J. Econ. Perspect. 15 (2), 213-238.

Department of Health and Human Services, 2013. Third Grade Follow Up of the Head Start Impact Study. Available online at: http://www.acf.hhs.gov/sites/ default/files/opre/head_start_executive_summary.pdf (accessed 10.12.13.).

DHHS, 2012. Third Grade Follow up to the Head Start Impact Study. Department of Health and Human Services. Available online at: http://www.acf.hhs.gov/sites/ default/files/opre/head_start_report.pdf (accessed 05.19.14.).

Doll, R., Peto, R., 1976. Mortality in relation to smoking: 20 years' observations on male British doctors. Br. Med. J. 2 (6051), 1525-1536.

Finn, J.D., Gerber, S.B., Achilles, C.M., 2001. The enduring effects of small classes, Teach. Coll. Rec. 103 (2).

Finn, J.D., Gerber, S.B., Boyd-Zaharias, J., 2005. Small classes in the early grades, academic achievement, and graduating from high school. J. Educ. Psychol. 97 (2), 214-22310.

Friedman, T., 2005. The World Is Flat. Macmillan, New York.

Fuchs, V., 2004. Reflections on the socio-economic correlates of health. J. Health Econ. 23, 653-661.

Galea, S., Tracy, M., Hoggatt, K.J., DiMaggio, C., Karpati, A., 2011. Estimated deaths attributable to social factors in the United States. Am. J. Public Health 101 (8).

Glennan, T.K., Bodilly, S.J., Galegher, J., Kerr, K.A., 2000. Expanding the Reach of Education Reforms: Perspectives from Leaders in the Scale-up of Educational Interventions, Rand Corporation.

Golembeski, C., Fullilove, R., 2005. Criminal (in)justice in the city and its associated health consequences. Am. J. Public Health 95 (10), 1701-1706. http://dx.doi.org/ 10.2105/AJPH.2005.063768 pii:AJPH.2005.063768.

Gottfredson, L.S., 2004. Intelligence: is it the epidemiologists' elusive "fundamental cause" of social class inequalities in health? J. Pers. Soc. Psychol. 86 (1), 174-199.

Grossman, M., 1997. Effects of education on health (with Robert Kaestner). In: Behrman, Jere R., Stacey, Nevzer (Eds.), The Social Benefits of Education. University of Michigan Press, Ann Arbor, Michigan.

Heckman, J.J., Moon, S.H., Pinto, R., Savelyev, P.A., Yavitz, A., 2010. The rate of return to the highscope Perry Preschool Program. J. Public Econ. 94 (1), 114-128.

Johnson, N.J., Sorlie, P.D., Backlund, E., 1999. The impact of specific occupation on mortality in the US National Longitudinal Mortality Study. Demography 36 (3), 355-367.

Kawachi, I., Adler, N.E., Dow, W.H., 2010. Money, schooling, and health: mechanisms and causal evidence. Ann. N. Y. Acad. Sci. 1186, 56-68. http://dx.doi.org/10.1111/ j.1749-6632.2009.05340.x pii:NYAS5340.

Kehrer, B.H., Wolin, C.M., 1979. Impact of income maintenance on low birth weight: evidence from the Gary Experiment. J. Hum. Resour. 14 (4), 434-462.

Kolb, B., Whishaw, I.Q., 2009. Fundamentals of Human Neuropsychology. Macmillan.

Krueger, A.B., Whitmore, D.M., 2001. The effect of attending a small class in the early grades on college-test taking and middle school test results: evidence from Project STAR. Econ. J. 111 (468)

Levin, H. Belfield, C., 2007. The Price We Pay: Economic and Social Consequences of Inadequate Education. Brookings Institution Press, Washington, D.C.

Levin, H., Belfield, C., Muennig, P., Rouse, C., 2006. The Costs and Benefits of an Excellent Education for America's Children. Teachers College, New York, p. 24.

Link, B.G., Phelan, J., 1995. Social conditions as fundamental causes of disease. J. Health Soc. Behav. 35, 80-94.

Liu, Y., Tanaka, H., 2002. Overtime work, insufficient sleep, and risk of non-fatal acute myocardial infarction in Japanese men. Occup. Environ. Med. 59 (7), 447-451.

Lleras-Muney, A., 2005. The relationship between education and adult mortality in the United States. Rev. Econ. Stud. 72 (1), 189-221.

Ludwig, J., Miller, D.L., 2007. Does head start improve children's life chances? Evidence from a regression discontinuity design. Q. J. Econ. 122 (1), 159-208. http://dx.doi.org/10.1162/qjec.122.1.159.

Martin, A.B., Lassman, D., Washington, B., Catlin, A., 2012. Growth in US health spending remained slow in 2010; health share of gross domestic product was unchanged from 2009. Health Aff. 31 (1), 208-219.

McEwen, B.S., 1998. Protective and damaging effects of stress mediators. N. Engl. J. Med. 338 (3), 171-179.

McEwen, B.S., Mirsky, A.E., 2002. How socioeconomic status may "get under the skin" and affect the heart. Eur. Heart J. 23 (22), 1727-1728. 
McLaughlin, A.E., Campbell, F.A., Pungello, E.P., Skinner, M., 2007. Depressive symptoms in young adults: the influences of the early home environment and early educational child care. Child. Dev. 78 (3), 746-756.

Mokdad, A.H., Marks, J.S., Stroup, D.F., Gerberding, J.L., 2004. Actual causes of death in the United States, 2000. J. Am. Med. Assoc. 291 (10), 1238-1245.

Muennig, P., 2007. How education produces health: a hypothetical framework. Teach. Coll. Rec. 14606, 1-17.

Muennig, P., Cohen, A.K., Palmer, A., Zhu, W., 2013. The relationship between five different measures of structural social capital, medical examination outcomes, and mortality. Soc. Sci. Med. 85, 18-26. http://dx.doi.org/10.1016/ j.socscimed.2013.02.007.

Muennig, P., Fiscella, K., Tancredi, D., Franks, P., 2010. The relative health burden of selected social and behavioral risk factors in the United States: implications for policy. Am. J. Public Health 100 (9), 1758-1764. http://dx.doi.org/10.2105/ AJPH.2009.165019.

Muennig, P., Johnson, G., Wilde, E.T., 2011a. The effect of small class sizes on mortality through age 29 years: evidence from a multicenter randomized controlled trial. Am. J. Epidemiol. 173 (12), 1468-1474. http://dx.doi.org/10.1093/aje/ kwr011.

Muennig, P., Robertson, D., Johnson, G., Campbell, F., Pungello, E.P., Neidell, M. $2011 \mathrm{~b}$. The effect of an early education program on adult health: the Carolina Abecedarian Project randomized controlled trial. Am. J. Public Health 101 (3), 512-516. http://dx.doi.org/10.2105/AJPH.2010.200063.

Muennig, P., Schweinhart, L., Montie, J., Neidell, M., 2009. Effects of a prekindergarten educational intervention on adult health: 37-year follow-up results of a randomized controlled trial. Am. J. Public Health 99 (8), 1431-1437. http:/ dx.doi.org/10.2105/AJPH.2008.148353.

Newhouse, J.P., Rand Corporation. Insurance Experiment Group, 1993. Free for All?: Lessons from the Rand Health Insurance Experiment. Harvard University Press, Cambridge, Mass.

Nores, M., Belfield, C.R., Barnett, W.S., Schweinhart, L., 2005. Updating the economic impacts of the high/scope Perry Preschool Program. Educ. Eval. Policy Anal. 27 (3), 245.

Olshansky, S.J. Antonucci, T. Berkman, L, Binstock, R.H. Boersch-Supan, A Cacioppo, J.T., Rowe, J., 2012. Differences in life expectancy due to race and educational differences are widening, and many may not catch up. Health Aff. Millwood 31 (8), 1803-1813. http://dx.doi.org/10.1377/hlthaff.2011.0746.

Ou, S.-R., Reynolds, A.J., 2008. Predictors of educational attainment in the Chicago Longitudinal Study. Sch. Psychol. Q. 23 (2), 199.

Palfrey, J.S., Hauser-Cram, P., Bronson, M.B., Warfield, M.E., Sirin, S., Chan, E., 2005 The Brookline early education project: a 25-year follow-up study of a familycentered early health and development intervention. Pediatrics 116 (1), $144-152$.

Pomerleau, O.F., Pomerleau, C.S., 2006. Research on stress and smoking: progress and problems. Br. J. Addict. 86 (5), 599-603.
Ramsden, S., Richardson, F.M., Josse, G., Thomas, M.S., Ellis, C., Shakeshaft, C. Price, C.J., 2011. Verbal and non-verbal intelligence changes in the teenage brain. Nature 479 (7371), 113-116.

Reynolds, A.J., Temple, J.A., Robertson, D.L., Mann, E.A., 2001. Long-term effects of an early childhood intervention on educational achievement and juvenile arrest: 15-year follow-up of low-income children in public schools. J. Am. Med. Assoc. 285 (18), 2339-2346.

Ross, C.E., Mirowsky, J., 1995. Does employment affect health? J. Health Soc. Behav 36 (3), 230-243.

Ross, C.E., Wu, C.L., 1995. The links between education and health. Am. Soc. Rev. 60 $719-745$.

Rundle, A., Neckerman, K.M., Freeman, L., Lovasi, G.S., Purciel, M., Quinn, J., Weiss, C. 2009. Neighborhood food environment and walkability predict obesity in New York city. Environ. Health Perspect. 117 (3), 442.

RWJF, 2008. Social Factors Have Effects Beyond Health. Robert Wood Johnson Foundation. Chart 18. Available online at: http://www.commissiononhealth. org/PDF/soc_factrs.pdf (accessed 26.07.14.).

Schnittker, J., Bacak, V., 2014. The increasing predictive validity of self-rated health. PLoS One 9 (1), e84933.

Schoeni, R.F., House, J.S., Kaplan, G.A., Pollack, H. (Eds.), 2008. Making Americans Healthier: Social and Economic Policy as Health Policy. Russell Sage Foundation, New York.

Schweinhart, L.J., 2004. The High/Scope Perry Preschool Study Through Age 40 High/Scope, Ypsilanti, p. 22.

Schweinhart, L.J., Montie, J., Xiang, Z., Barnett, W.S., Belfield, C., Nores, M., 2005. The High/Scope Perry Preschool Study Through Age 40. High/Scope Press, Ypsilanti, MI.

Stone, D., 1997. Policy Paradox: The Art F Political Decision Making. WW Norton, New York.

Turkheimer, E., Haley, A., Waldron, M., Onofrio, B., Gottesman, I.I. 2003. Socioeconomic status modifies heritability of IQ in young children. Psychol. Sci. 14 (6) 623-628.

Wilson, M.E., Fisher, J., Fischer, A., Lee, V., Harris, R.B., Bartness, T.J., 2008. Quantifying food intake in socially housed monkeys: social status effects on caloric consumption. Physiol. Behav. 94 (4), 586-594.

Wong, M.D., Shapiro, M.F., Boscardin, W.J., Ettner, S.L., 2002. Contribution of major diseases to disparities in mortality. N. Engl. J. Med. 347 (20), 1585-1592.

Woolf, S.H., Johnson, R.E., Phillips Jr., R.L., Philipsen, M., 2007. Giving everyone the health of the educated: an examination of whether social change would save more lives than medical advances. Am. J. Public Health 97 (4), 679-683. http:/ dx.doi.org/10.2105/AJPH.2005.084848 pii:AJPH.2005.084848.

Zellner, A., 1962. An efficient method of estimating seemingly unrelated regressions and tests for aggregation bias. J. Am. Stat. Assoc. 57 (298), 348-368. 